\title{
Análise integrativa sobre o processo administrativo disciplinar e o princípio da eficiência
}

\author{
Integrative analysis of the disciplinary administrative process and the principle of efficiency \\ Análisis integradora del proceso administrativo disciplinario y el principio de eficiencia
}

Recebido: 22/03/2021 | Revisado: 29/03/2021 | Aceito: 01/04/2021 | Publicado: 11/04/2021

Ederluiz Martins

ORCID: https://orcid.org/0000-0003-3729-8245 Universidade Federal dos Vales do Jequitinhonha e Mucuri, Brasil E-mail: ederluiz.martins@ufvjm.edu.br

Carlos Alberto Dias

ORCID: https://orcid.org/0000-0002-5286-6637 Universidade Federal dos Vales do Jequitinhonha e Mucuri, Brasil E-mail: carlos.dias@ufvjm.edu.br

Ciro Meneses Santos

ORCID: https://orcid.org/0000-0001-8687-0987 Universidade Federal dos Vales do Jequitinhonha e Mucuri, Brasil E-mail: cirosantos@gmail.com

Marcio Coutinho de Souza

ORCID: https://orcid.org/0000-0002-4238-1572 Universidade Federal dos Vales do Jequitinhonha e Mucuri, Brasil E-mail: marcio.souza@ufvjm.edu.br Luiz de Souza Gomes

ORCID: https://orcid.org/0000-0002-0307-7041 Universidade Federal dos Vales do Jequitinhonha e Mucuri, Brasil E-mail: profluizgomes@hotmail.com

\begin{abstract}
Resumo
A reforma administrativa trazida pela Emenda Constitucional (EC) 19/98 positivou no ordenamento jurídico brasileiro o princípio da eficiência. Os gestores públicos devem se pautar, desde então, pelo primado da legalidade, impessoalidade, moralidade, publicidade e por uma administração eficiente. O Processo Administrativo Disciplinar (PAD) é fulcral para o administrador público, pois é com essa ferramenta que ele poderá fazer o controle disciplinar dos servidores públicos, pessoas que fazem o serviço público chegar até a sociedade. O trabalho tem o objetivo verificar a partir de uma revisão integrativa como está caracterizada a eficiência administrativa no contexto da administração pública, processo administrativo e princípio da eficiência aplicados ao processo administrativo disciplinar, levando em consideração artigos com Qualis CAPES A1 a B4, publicados no período de 2010 a 2020. Foi utilizado o método de revisão integrativa de literatura, com busca de estudos relacionados ao tema, em plataformas com periódicos indexados, com data de publicação entre os anos de 2010 a 2020, essa busca foi realizada durante o segundo semestre de 2020. Para tanto utilizou-se os seguintes descritores, Processo Administrativo Disciplinar, PAD, Eficiência na Administração Pública, Eficiência no Processo Administrativo Disciplinar, Eficiência e Melhoria da Gestão.
\end{abstract}

Palavras-chave: Administração pública; Eficiência; Processo administrativo disciplinar; Administrador público.

\begin{abstract}
The administrative reform brought about by the Constitutional Amendment (EC) 19/98 positivity in the Brazilian legal system the principle of efficiency. Public managers must, since then, be guided by the primacy of legality, impersonality, morality, publicity and by an efficient administration. The Disciplinary Administrative Process (PAD) is central to the public administrator, because it is with this tool that he can make the disciplinary control of public servants, people who make the public service reach society. $\mathrm{O}$ work item or objective to verify from an integrative review how it is characterized by administrative efficiency not in the context of public administration, administrative process and the principle of efficiency applied to the disciplinary administrative process, taking into consideration articles with Qualis Capes A1 to B4 published no period from 2010 to 2020. The method of integrative literature review was used, with a search for studies related to the theme, on platforms with indexed journals, with publication date between the years 2010 to 2020, this search was carried out during the second semester of 2020. the following descriptors are included, Disciplinary Administrative Process, PAD, Efficiency in Public Administration, Efficiency in the Disciplinary Administrative Process, Efficiency and Management Improvement.
\end{abstract}

Keywords: Public administration; Efficiency; Disciplinary administrative procedure; Public manager. 


\begin{abstract}
Resumen
La reforma administrativa provocada por la Enmienda Constitucional (CE) 19/98 positividad en el ordenamiento jurídico brasileño el principio de eficiencia. Los gestores públicos deben, desde entonces, guiarse por la primacía de la legalidad, la impersonalidad, la moral, la publicidad y por una administración eficiente. El Proceso Administrativo Disciplinario (PAD) es central para el administrador público, porque es con esta herramienta que puede hacer que el control disciplinario de los servidores públicos, personas que hacen que el servicio público llegue a la sociedad. El trabajo tiene como objetivo comprobar a partir de una revisión integradora sobre cómo se caracteriza la eficiencia administrativa en el contexto de la gestión pública, el proceso administrativo y el principio de eficiencia aplicado al proceso administrativo disciplinario, teniendo en cuenta los artículos con Qualis Capes A1 a B4 publicados en el período 2010 a 2020. Se utilizó el método de revisión integradora de la literatura, con la búsqueda de estudios relacionados con la temática, en plataformas con revistas indexadas, con fecha de publicación entre los años 2010 a 2020, esta búsqueda se realizó durante el segundo semestre de 2020. los siguientes descriptores Se utilizan, Proceso Administrativo Disciplinario, PAD, Eficiencia en la Administración Pública, Eficiencia en el Proceso Administrativo Disciplinario, Eficiencia y Mejoramiento de la Gestión.
\end{abstract}

Palabras clave: Administracion publica; Eficiencia; Procedimiento administrativo disciplinario; Gerente público.

\title{
1. Introdução
}

O presente artigo trata do Processo Administrativo Disciplinar (PAD) e seus desdobramentos, especialmente com relação à aplicação da eficiência administrativa. Este é um importante instrumento para a Administração Pública Brasileira, pelo qual o administrador público exerce o controle disciplinar dos seus administrados, os servidores públicos, que no caso deste trabalho são os servidores públicos civis na esfera federal. Também, constitui ferramenta de extrema relevância para o servidor público, que poderá provar sua inocência resguardando assim a probidade administrativa.

Segundo Cândido Junior (2011, p. 233) "os gastos públicos geram impactos no crescimento econômico, a população espera melhor utilização dos recursos, pois existem limites para a expansão das receitas que financiam o aumento dos gastos per capita".

O tema da eficiência na Administração Pública passou a ser discutido a partir da Reforma Administrativa aprovada pelo Decreto-Lei 200/1967 que sujeitou a administração indireta ao controle da eficiência administrativa. Com a promulgação da Emenda Constitucional 19/98, o princípio da eficiência da Administração Pública foi positivado na Constituição Federal de 1988 através do art. 37, caput, desta Carta Magna. Esta Emenda veio com uma série de medidas no intuito de reformar a Administração Pública para torná-la mais eficiente, por meio da redução de gastos e obtenção de melhores resultados (Limberger \& Kossmann, 2016, p. 292).

Um ano depois, a Lei 9.784/99, que trata do processo administrativo em âmbito federal, em seu Artigo $2^{\circ}$, inseriu a eficiência como um dos princípios norteadores do Processo Administrativo. Desta forma tornaram-se mais fortes os mecanismos de controle social do poder, sendo estes princípios considerados fundamentais para o entendimento, bem como para a interpretação de algumas áreas do Direito, principalmente do Direito Público (Limberger \& Kossmann, 2016, p. 298; Cury-Mendes, 2015, p. 137).

Na seara do Direito Público encontra-se o Direito Administrativo, que regulamenta toda a atividade administrativa pública e por consequência, os seus agentes. $\mathrm{O}$ administrador público tem como obrigação atuar em consonância com os princípios da juridicidade, legalidade, moralidade, eficiência, boa-fé, probidade, entre outros (Siqueira \& Rosolen, 2017). "Vale destacar que esses princípios dão amparo normativo às atividades realizadas pelo sistema de controle interno de cada instituição, se praticados nos referenciados moldes" (Carvalho, \& et al., 2020, p. 5).

O Processo Administrativo Disciplinar é corolário do Direito Administrativo Disciplinar, ramo do Direito Administrativo. Neste tipo de processo a Administração Pública apura as infrações cometidas por seus servidores. Para atuar de forma coerente com o princípio da eficiência, a Administração Pública deverá observar o trâmite do processo dentro do prazo estabelecido e o resultado justificado, além de resguardar todos os direitos ao servidor acusado no processo disciplinar (Bocchino et al., 2016). 
Isto posto, para o presente estudo, pretende-se responder a seguinte questão: como está caracterizada a eficiência administrativa no contexto da administração pública, processo administrativo e princípio da eficiência aplicados ao processo administrativo disciplinar?

Logo, diante de um contexto de escassez, essa questão indaga explicitamente a necessidade de eficiência no processo administrativo disciplinar (Dantas \& Silva, 2019). Dessa forma, o presente trabalho tem por objetivo verificar a partir de uma revisão integrativa como está caracterizada a eficiência administrativa no contexto da administração pública, processo administrativo e princípio da eficiência aplicados ao processo administrativo disciplinar, levando em consideração artigos com Qualis CAPES A1 a B4, publicados no período de 2010 a 2020.

$\mathrm{O}$ presente o artigo está estruturado nas seguintes seções: introdução, problema e objetivos da pesquisa; referencial teórico; métodos; análise de dados - análise textual; considerações finais e referências.

\section{Referencial Teórico}

As discussões nessa seção propõem trazer a fundamentação teórica sobre a temática pesquisada. Irá tratar de modo resumido os principais temas que envolvem o objeto do estudo. Inicialmente tratara da Administração pública principalmente com relação as suas mudanças com o passar dos anos. Em seguida versará sobre a eficiência no serviço público, o processo administrativo de modo geral e por fim o processo administrativo disciplinar.

\subsection{Administração pública no Brasil}

A administração pública brasileira sofreu várias mudanças (reformas) ao passar dos anos. Segunda Paula (2005) devido a tradição patrimonialista, os interesses pessoais regiam as ligações com os bens e serviços públicos, situação que teve suas primeiras tentativas de mudança no governo de Vargas, onde em 1933 foi criado o Departamento de Administração do Serviço Público (Dasp). Entre 1945 e o golpe de 64, segundo a autora, havia traços de cultura política patrimonial e bolsões de eficiência administrativa. No período militar (1964-85) foi possível melhorar a máquina administrativa, através de técnicas de racionalização. Contudo, para autora, o que ela chamou de tecnocracia, se caracterizou por um patrimonialismo moderno ou neopatrimonialismo.

Após o período militar havia uma preocupação dos atores políticos com a redemocratização, e em corrigir os erros cometidos pelos militares. Sendo assim, mudanças importantes na administração pública foram feitas no final da década de 1980, tais como as reformas nas finanças públicas, fim da 'conta movimento' e criação da Secretaria do Tesouro nacional. Contudo, as mudanças mais profundas vieram somente com a promulgação da Constituição de 1988, que promoveu a democratização do Estado, descentralização político, financeira e administrativa, e a proposta de completar a reforma do serviço civil (Abrucio, 2007, 'grifo do autor').

No período Collor (1990-1992) a percepção de uma série de problemas com administração pública foi transformada nas ideias de Estado mínimo e combate aos marajás, mas essas medidas não foram bem-sucedidas:

As medidas tomadas nesse período foram um desastre. Houve o desmantelamento de diversos setores e políticas públicas, além da redução de atividades estatais essenciais. Como o funcionário público foi transformado no bode expiatório dos problemas nacionais, disseminou-se uma sensação de desconfiança por toda a máquina federal, algo que produziu uma lógica do "salve-se quem puder". Foi neste contexto que, paradoxalmente, se constituiu um regime jurídico único extremamente corporativista (Abrucio, 2007, p. 70, "grifo do autor").

Com o governo de Fernando Henrique Cardoso (FHC) a administração pública brasileira entrou em uma outra fase de reforma, conhecida com Nova Gestão Pública ou Administração Gerencial, inspirada nas reformas que já estavam acontecendo 
em outros países, como Inglaterra, Estados Unidos, Austrália e Nova Zelândia:

Com o objetivo de aproximar o modelo de gestão pública ao modelo de gestão privada, nasceu no início dos anos 80 , no Reino Unido, A New Public Management (NPM). A NPM ou NGP - Nova Gestão pública - constituiu-se num movimento de reforma e modernização administrativa experimentada pelos vários países da OCDE, com origem no managerialism que, segundo Carvalho (2001), reconhecia o exercício de uma melhor gestão como a solução eficaz para os males sociais e econômicos (Correa, Mendes \& Silva, 2019, p. 33, grifos nosso).

Neste sentido, corroborando com ideia da reforma inspirada em outros países o autor Saraiva (2010, p. 2), destaca:

As décadas de 80 e 90 foram ricas em experiências de reforma do Estado. De um modo geral, elas apontaram para reduzir o tamanho da administração pública, tanto no número de funcionários, como no de atividades desempenhadas pelo Estado. A inspiração principal partiu das reformas empreendidas pelo Presidente Ronald Reagan nos Estados Unidos e pela Primeira Ministra Margareth Thatcher no Reino Unido, e se consolidaram com o plano de reforma do Presidente Clinton, dirigido pelo seu vice presidente Al Gore (1995).

Para implementação das reformas, o governo de FHC criou o Ministério da Administração Federal e Reforma do Estado (MARE) e nomeou como ministro Luiz Carlos Bresser Pereira, que lançou o Plano Diretor de Reforma do Aparelho do Estado (PDRAE), conforme esclarecem Pinto e Behr (2015, p. 767):

No Brasil, o governo copiou alguns modelos em busca da eficiência na máquina pública, influenciado principalmente pelas alterações estruturais que ocorriam nos países desenvolvidos. Em 1995, no governo FHC, o então Ministro da Administração Federal e Reforma do Estado, Luiz Carlos Bresser-Pereira, lançou o PDRAE.

Esta reforma também ficou conhecida como reforma Bresser e com ela registrou-se muitos avanços, entre eles, podese destacar uma considerável reorganização administrativa do governo federal, principalmente com relação as informações da administração pública, houve também fortalecimento das carreiras de Estado, realização de concursos públicos e capacitação dos servidores. Num segundo momento da reforma Bresser, foram feitas mudanças legais, principalmente com as Emendas Constitucionais $n^{\circ} 19$ e 20, que fizeram alterações no teto de gasto do funcionalismo, no Regime Jurídico Único e a positivação do princípio da eficiência (Abrucio, 2007).

A administração do governo Lula continuou a agenda de reformas, dando continuidade a algumas ações propostas no governo anterior e ampliando outras:

Segundo o documento Gestão pública para um Brasil de todos, o governo Lula teria como propósito reestruturar o serviço público a partir de duas vertentes: o de fazer frente às demandas sociais e tornar o Estado mais "eficiente, inclusivo e eqüitativo". Dentro de tal perspectiva inclui-se o funcionalismo público, isto é, como operador da reorganização desejada. Para tanto, são propostas várias medidas que visam fomentar uma política de recursos humanos.

O mesmo documento defende, no que diz respeito à estruturação da administração pública, a realização de determinadas "intervenções", quais sejam: recomposição da força de trabalho no setor público; redesenho dos sistemas de cargos, carreiras, benefícios e concursos; realinhamento de salários; definição de política de capacitação técnica e gerencial permanente de servidores; promoção de ações visando a saúde ocupacional e o redesenho de estruturas e processos de trabalho [...] (Brasil, 2003 apud Gomes, Silva \& Sória, 2011, p. 172, "grifos do autor").

Sendo assim a Administração Pública contemporânea se mostra mais de acordo com as expectativas dos usuários, podendo ser defina como, segundo Maffini (2009), o termo administração pública é para designar uma atividade estatal voltada à consecução de fins constitucionais sensíveis impostos ao Estado, caraterizada por uma estrutura integrada de um conjunto de órgãos ou entidades determinadas à realização desses fins.

Já o autor Saraiva (2010), por sua vez, explana que a administração pública, diferentemente da privada, atua seguindo princípios gerais constantes na CRFB de 1988, com isso segue sistemas mais rígidos de planejamento governamental e modernamente, por sistemas de elaboração de política pública. Ressalta ainda que existem, no setor público, planejamentos 
mais abrangentes em alguns setores específicos como o elétrico, transporte, espacial, entre outros.

Di Pietro (2014) colabora informando que Administração Pública atua por meio de dois sentidos, a saber: o primeiro sentido Subjetivo, Formal ou Orgânico, que significa a designação dos entes que exercem a atividade administrativa, as pessoas jurídicas, órgãos e agentes públicos incumbidos de exercer a função pública; o segundo sentido Objetivo, Material ou Funcional designa a natureza da atividade administrativa que os agentes públicos exercem em sua prática diária.

Pelo exposto acima tem-se que a Administração Pública Brasileira passou por reformas para acompanhar o dinamismo da sociedade, sempre em busca de melhorar os serviços prestados aos cidadãos. Nessa busca de melhorias utilizouse de mecanismos da administração privada, porém tendo sempre em mente que a administração pública tem objetivos e fins diferentes da privada. A qualidade do serviço público depende de vários fatores, o principal deles refere-se à eficiência, tema que será tratado a seguir.

\subsection{A eficiência no serviço público}

O tema da eficiência na Administração Pública passou a ser discutido a partir da Reforma Administrativa aprovada pelo Decreto-Lei 200/1967 que sujeitou a administração indireta ao controle da eficiência administrativa. Mas, para efeito da Administração Pública como um todo, foi com a promulgação da Emenda Constitucional 19/98 que positivou o princípio da eficiência da Administração Pública na Constituição Federal de 1988 através do art. 37, caput, que a eficiência na Administração Pública ganha destaque. Esta Emenda veio com uma série de medidas no intuito de reformar a Administração Pública para torná-la mais eficiente, por meio da redução de gastos e obtenção de melhores resultados (Limberger \& Kossmann, 2016).

A eficiência na Administração pública constitui uma obrigação e consequência lógica do serviço prestado pelo Estado ao cidadão, não somente após a positivação no Art. 37 da Carta Política, mas muito antes disso (Silva, 2011). Neste sentido para Lima (2015, p. 279) "o fato de a eficiência ter sido incluída na redação do art. 37 da CF como um princípio geral da Administração Pública apenas em 1998, não significa que alguma vez a Administração esteve autorizada a agir com deszelo".

Nesse cenário, para Aguiar \& Haber (2015) a Administração Pública seguindo os ditames do princípio da eficiência deverá organizar, estruturar e disciplinar suas ações, com o objetivo de alcançar os melhores resultados na prestação do serviço público. Neste caso o gestor deverá agir de modo rápido e preciso no intuito de produzir resultados satisfatórios à população.

Para Siqueira e Rosolen (2017) a aplicação da eficiência na Administração Pública impõe que sejam usados os recursos de forma adequada no intuito de atingir os objetivos do Estado. Deve haver um planejamento das ações do Estado e sua execução deverá ser de modo que possibilite a modificar realidades sociais como a pobreza e desigualdade. Neste mesmo sentido Camargo \& Guimarães (2013, p. 142) destacam que:

[...] Não é suficiente usar com economia, zelo e dedicação os bens e os recursos públicos, mas também se faz necessária a produção de eficácia, ou seja, comprometimento político e institucional com um planejamento competente, ocasionando a obtenção de resultados sociais aspirados pela sociedade oferecendo serviços de interesse social compatíveis com suas necessidades em extensão, qualidade e custos.

Também deve-se observar que o serviço público para ser eficiente deverá se pautar pelos princípios constitucionais voltados para esse fim, evitando a busca de resultados baseados em uma lógica voltada ao setor privado. Como visto, ao Estado cabe a persecução do bem comum, o interesse social e diminuição das desigualdades, neste sentido destaca Limberger e Kossman (2016, p. 302, "grifo do autor"):

Assim, também não basta apenas a realização e a concretização dos resultados que se pretende alcançar, com uma prática administrativa eficiente nos moldes do programa de "qualidade total", mas também o respeito aos meios que 
devem ser utilizados, em observância aos princípios da legalidade, da publicidade e outros.

Conforme discutido nesta seção, a eficiência no serviço público faz-se necessária para cumprir o principal fim do Estado que é o bem-estar social, e isso só será possível com a utilização dos recursos de forma racional e com eficácia. Assim, a eficiência é necessária para a obtenção dos resultados almejados pela população. Nesse aspecto, a instrução do PAD, quando aplicado o princípio da eficiência administrativa poderá corroborar para melhorias na Administração Pública. Para melhor explicitar essa relação na próxima seção será contextualizado sobre o PAD.

\subsection{Processo administrativo disciplinar}

O Processo Administrativo, seguindo a lógica de estruturação de todo processo, forma-se através de documentos sequenciais que relatam as ações ou omissões constantes nos autos. $\mathrm{O}$ que se pode registrar como fator que irá diferenciar um processo administrativo dos demais processos é que aquele tramita exclusivamente pela administração pública, o que lhe traz algumas especificidades. Destarte, a Administração Pública utiliza o processo administrativo para dialogar com seus administrados, que podem ser servidores públicos ou não, como por exemplo o caso de discentes no caso de uma Instituição de Ensino (Bocchino et al., 2016).

Para Medauar (2018, p. 159) "[...] o processo administrativo caracteriza-se pela atuação dos interessados, em contraditório, seja ante a própria Administração, seja ante outro sujeito (administrado em geral, licitante, contribuinte, por exemplo) todos, neste caso, confrontando seus direitos ante a Administração".

O PAD é uma modalidade do processo administrativo, já que no PAD pode-se observar a participação dos interessados no contraditório e também é possível que os desdobramentos do processo interfiram na esfera jurídica dos cidadãos envolvidos (Bacellar Filho \& Hachem, 2010).

O processo disciplinar é a ferramenta que tem a Administração para a apuração de faltas e irregularidades cometidas por seus servidores. É através do processo administrativo disciplinar que a administração pública pode infligir sanções disciplinares aos seus agentes, por isso a obrigação de observar os princípios e garantias que lhes são impostas, bem como o procedimento próprio, para que possa ser utilizado com validade e eficácia (Souza, 2015, p. 31).

"Os limites da administração para apurar e responsabilizar o servidor público no processo administrativo disciplinar por atos praticados na vida privada estão elencados taxativamente no art. 148 da Lei 8.112/90" (Rocha, 2018, p. 18). Dessa forma, no PAD a Administração Pública fará a apuração das possíveis infrações cometidas por servidor público. O PAD tornou-se necessário tendo em vista que com o advento da Constituição de 1988, não se pode aplicar qualquer sanção ao servidor público pelo critério da 'verdade sabida', onde o administrador público podia aplicar sanções leves ao servidor, se tivesse o conhecimento direto da falta cometida (Medauar, 2018, p. 311, 'grifo nosso').

"O processo administrativo disciplinar é formado por uma conjugação de atos administrativos dotados de elementos e pressupostos materiais direcionados à concreção do escopo da persecução disciplinar" (Dezan \& Carmona, 2015, p. 527).

Corroborando com ideia da dinâmica processual presente no PAD, afirma Rezende (2017, p. 239):

A processualidade, assim, é a lógica que opera para chegar a uma conclusão final, que, no caso do direito administrativo disciplinar, é a imposição de uma sanção ao servidor. É o requisito para a eficaz apuração dos fatos, os quais, uma vez corretamente apurados, subsumir-se-ão, ou não, a determinada conduta tipificada na lei.

Neste sentido, na seara da administração pública federal a aplicação de penalidade ao servidor que comete alguma 
infração prevista em lei, será sempre precedida de um processo administrativo disciplinar, conforme preceitua a Constituição da República Federativa do Brasil (CRFB) de 1988 em seu Artigo nº 41, § $1^{\circ}$, inciso II, in verbis:

Art. 41. São estáveis após três anos de efetivo exercício os servidores nomeados para cargo de provimento efetivo em virtude de concurso público.

$\S 1^{\circ} \mathrm{O}$ servidor público estável só perderá o cargo:

I - em virtude de sentença judicial transitada em julgado;

\section{II - mediante processo administrativo em que lhe seja assegurada ampla defesa;}

III - mediante procedimento de avaliação periódica de desempenho, na forma de lei complementar, assegurada ampla defesa. (Brasil, 1988, grifo nosso)

Nota-se na norma supra que além da previsão da instauração do PAD, este deverá assegurar a ampla defesa. Sendo assim, entende-se que os servidores públicos de todos os entes da federação estão sujeitos às sanções disciplinares regulamentadas pela legislação.

Em especial, os servidores públicos civis federais têm na Lei $\mathrm{n}^{\circ} 8.112 / 90$ a regulamentação dos seus direitos e deveres, bem como as sanções, em caso de cometimento de infrações disciplinares. Para que um servidor infrator possa cumprir a sanção designada deve-se primeiro instaurar um PAD, mediante uma comissão nomeada pelo gestor máximo do órgão, para esse fim, momento que lhe será assegurado o direito de defesa, conforme a letra da lei no $\$ 3^{\circ}$ do Artigo 143 , combinado com o Artigo 149 (Brasil, 1990).

As comissões processantes, que são nomeadas para a condução do PAD, são formadas por servidores públicos, utilizando como critérios para a escolha destes os estáveis, devendo ter o presidente da comissão cargo de nível superior ou de mesmo nível, ou ter nível de escolaridade igual ou superior ao do indiciado, seguindo a norma do Artigo 149 da Lei ${ }^{\circ}$ 8.112/90 (Brasil, 1990). Nota-se que não há critérios para escolha de servidores com conhecimento técnico para condução de processo administrativo, mesmo esse tendo todas as garantias processuais de índole constitucional do processo judicial. Na maioria das vezes, os membros das comissões não possuem condições técnicas ou psicológicas para conduzirem um processo administrativo (Gomes, 2014).

Em relação ao direito de defesa assegurado pela Carta Magna para os processados administrativamente, cabe ressaltar que no PAD, é facultado ao servidor o direito de realizar uma defesa técnica por advogado, podendo também escolher fazer sua autodefesa em observância o que preceitua o Artigo 156 da Lei no 8.112/90 (Brasil, 1990). Neste sentido o Plenário do Supremo Tribunal Federal, em 07 de maio de 2008, aprovou sua Súmula Vinculante n 5 com a seguinte redação: "A falta de defesa técnica por advogado no processo administrativo disciplinar não ofende a Constituição". Entretanto para Bacellar \& Hachem (2010) interpretando a norma infraconstitucional pelos princípios da CRFB de 1988, os autores entendem que somente um advogado possui condições necessárias para uma defesa efetiva no PAD.

Nesta seção foram trazidas algumas definições do PAD e sua relevância para a administração pública brasileira. Este é um importante instrumento para os gestores públicos e também para o servidor que poderá apresentar sua defesa. Como instrumento da administração pública este deverá se pautar por alguns princípios administrativos e no caso deste estudo o princípio da eficiência.

\subsubsection{O princípio da eficiência aplicado ao processo administrativo disciplinar}

A eficiência na administração pública, conforme já discutido anteriormente, prevê processos menos morosos e com diminuição de gastos. O PAD é corolário do processo administrativo que por sua vez é o meio legítimo da administração pública exercer a função administrativa: 
Como garantia constitucional, o processo administrativo pode ser inicialmente conceituado como a forma da função administrativa, isto é, o modo por intermédio do qual ocorre o exercício da função administrativa. Nesse viés, o processo administrativo tem por objetivo a legitimação do poder. Isto é, somente pelo respeito aos institutos, procedimentos e garantias que compõe o devido processo legal administrativo é que se torna autêntico o exercício do Poder (Almeida Junior \& Pinto, 2015, p. 3).

Essa legitimação contida no processo administrativo, por parte da administração pública, também compreende o dever-poder disciplinar, podendo-se aferir que somente pelo PAD a administração pública pode punir o seu administrado:

[...] o procedimento e o processo administrativo compreendem a sede própria, legítima e adequada de atuação da Administração, como único meio de ação administrativa de resolução de conflitos, que mescle e coloque em "paridade de armas" "poderes" administrativos e direitos e garantias dos administrados, para o reconhecimento dessa função administrativa, a função sancionadora, pelo Estado Democrático de Direito - forma de legitimação do exercício do dever-poder disciplinar e de sua atividade punitiva interna corporis e sancionadora geral (Dezan \& Carmona, 2017, p. 215, "grifos do autor").

Sendo assim o processo administrativo está sujeito aos princípios administrativos constitucionais. A observância dos princípios administrativos, no que se refere à formalidade dos atos processuais, pode garantir o bom desenvolvimento dos procedimentos formais da Administração Pública. Com isso, busca-se evitar o crescente questionamento, por parte do Poder Judiciário, e também pela própria administração pública, de processos administrativos que possam estar maculados por vícios insanáveis de irregularidades, levando à anulação dos mesmos. Assim, é importante a identificação de tais princípios para que os administradores públicos orientem a sua equipe de trabalho, a fim de evitar anulações dos processos administrativos, que tramitam nas repartições públicas (Cury-Mendes, 2015).

Pode-se constatar também que com relação aos princípios processuais constitucionais, que o constituinte visou assegurar a igualdade entre processo judicial e administrativo (Art. $5^{\circ}$ inciso LV CFRB de 1988). Neste sentido é dever da Administração Pública seguir os ditames legais constitucionais, como esclarece Bacellar Filho e Hachem (2010, p. 44):

Ora, o art. $5^{\circ}$, LV da CF não faz diferenciação alguma entre o processo judicial e o processo administrativo, quando trata dos direitos ao contraditório e à ampla defesa. Consequentemente, se não há qualquer distinção, pressupõe-se que o regime principiológico aplicável a cada um deles e o conteúdo jurídico dos direitos fundamentais incidentes em ambas as categorias processuais deve ser exatamente o mesmo.

O princípio da eficiência, norteador da busca por melhores resultados pela administração pública, também tem sua influência no processo administrativo, inclusive na sua finalidade:

O processo administrativo tem por finalidades: a) assegurar uma atuação administrativa eficiente, através da disciplina dos meios pelos quais a Administração Pública toma decisões, pois o pré-estabelecimento de um caminho a seguir representa, ao lado de segurança jurídica, importante fator de economia processual, e b) garantir a maximização dos direitos dos administrados (Almeida Junior \& Pinto, 2015, p. 5).

Seguindo essa mesma lógica, sendo o PAD um ramo do processo administrativo, deverão ser observados tanto os princípios administrativos quanto os princípios processuais constitucionais. No caso deste artigo, destaca-se o princípio da eficiência como ferramenta principal da administração pública para basilar a dinâmica processual.

Neste sentido Bocchino et al., (2016) esclarece que, em se tratando de PAD, para atuar de forma coerente com o princípio da eficiência, a Administração Pública deverá observar o trâmite do processo dentro do prazo estabelecido e o resultado justificado, além de resguardar todos os direitos ao servidor acusado no processo disciplinar. 


\section{Materiais e Métodos Aplicados na Pesquisa}

Para essa pesquisa foi realizado uma revisão integrativa de literatura. Esse método de pesquisa objetiva traçar uma análise sobre o conhecimento já construído em pesquisas anteriores sobre um determinado tema. A revisão integrativa permite que seja feita uma síntese de vários artigos publicados, possibilitando a geração de novos conhecimentos (Botelho, Cunha \& Macedo, 2011, p. 127).

"A revisão integrativa é constituída de cinco etapas distintas, tais como, o estabelecimento do problema; a seleção da amostra; a caracterização dos estudos; as análises e discussão dos resultados; e a apresentação" (Ganong, 1987; Beyea \& Nicoll, 1998 apud Sobrinho, \& et al., 2020, p. 5). Assim nesse artigo para a utilização desse método, primeiro foi determinado a questão a ser respondida, objetivo específico e só assim realizada a busca, no intuito de identificar e coletar o máximo de estudos de relevância para o tema proposto, utilizando dos critérios de inclusão e exclusão previamente definidos.

Para o levantamento bibliográfica do Estudo, realizado no segundo semestre do ano de 2020, fez-se uma busca em plataformas com periódicos indexados, com data de publicação entre os anos de 2010 a 2020. No levantamento dos artigos, levando em consideração a relação com a temática proposta, foram utilizados como descritores os termos Processo Administrativo Disciplinar, PAD, Eficiência na Administração Pública, Eficiência no Processo Administrativo Disciplinar, Eficiência e Melhoria da Gestão Pública.

Como critérios de inclusão propostos para este estudo, os artigos deveriam estar disponíveis gratuitamente para download em formato PDF, totalmente voltados ao objeto de estudo, publicados entre os anos de 2010 a 2020 em revistas científicas e revisados por pares.

Após a primeira análise baseada nos critérios de inclusão e exclusão e realizando uma leitura exploratória dos resumos, foram selecionados 45 artigos. Em seguida foi feita uma leitura na integra dos artigos, restando 20 para artigos com temática considerada totalmente voltada para o estudo proposto.

A compilação de informações em meios eletrônicos é um grande avanço para os pesquisadores, democratizando o acesso e proporcionando atualização frequente, tendo como propósito reunir o conhecimento sobre o tópico pesquisado (Souza Silva \& Carvalho, 2010, p. 103).

Após a seleção dos 20 artigos foram coletas informações sendo estas catalogadas em uma planilha eletrônica do programa Libre Office versão 6.3.6.2, utilizando as seguintes variáveis: autor (es) e ano, Título do artigo, Revista que foi publicado, classificação Qualis (Quadriênio 2013-2016), objetivo, principais considerações.

\section{Resultados e Discussão}

Nesta seção será feita uma análise dos artigos selecionados, com base nos critérios de inclusão e exclusão, que foram considerados de maior relevância para o estudo da temática pesquisada - Eficiência no Processo Administrativo Disciplinar. O Quadro 1 traz algumas das características dessas publicações sendo elas: autor e ano, títulos das publicações, o nome revista em que foram publicados e suas classificações no Qualis CAPES. No total foram identificadas 20 publicações. 
Quadro 1 - Caracterização das principais publicações sobre a temática.

\begin{tabular}{|c|c|c|c|c|}
\hline Cód & Autor \& Ano & Título & Revista & Qualis \\
\hline 01 & $\begin{array}{l}\text { Bacellar Filho \& Hachem } \\
\text { (2010) }\end{array}$ & $\begin{array}{l}\text { A necessidade de defesa técnica no PAD e a } \\
\text { inconstitucionalidade da Súmula Vinculante }{ }^{\circ} 5 \text { do STF }\end{array}$ & $\begin{array}{l}\text { A\&C. Revista de D. } \\
\text { Administrativo \& } \\
\text { Constitucional }\end{array}$ & A 2 \\
\hline 02 & $\begin{array}{c}\text { Camargo \& } \\
\text { Guimarães (2013) }\end{array}$ & O princípio da eficiência na Gestão Pública & $\begin{array}{l}\text { CEPPG REVISTA } \\
\text { (CATALÃO) }\end{array}$ & B3 \\
\hline 03 & $\begin{array}{l}\text { Bacellar filho \& Pivetta } \\
\text { (2014) }\end{array}$ & $\begin{array}{l}\text { O regime jurídico do processo administrativo na Lei } \mathrm{n}^{\circ} \\
9.784 / 99\end{array}$ & $\begin{array}{l}\text { A\&C. Revista de D. } \\
\text { Administrativo \& } \\
\text { Constitucional }\end{array}$ & A2 \\
\hline 04 & Barros (2015) & $\begin{array}{l}\text { Processo, precedentes e as novas formas de justificação da } \\
\text { Administração Pública Brasileira }\end{array}$ & $\begin{array}{l}\text { Revista Digital De Direito } \\
\text { Administrativo }\end{array}$ & B4 \\
\hline 05 & Cury-Mendes (2015) & $\begin{array}{l}\text { Princípios do Processo Administrativo Federal e a } \\
\text { formalidade dos atos processuais: uma discussão com foco } \\
\text { no desenvolvimento }\end{array}$ & $\begin{array}{l}\text { Revista Brasileira De } \\
\text { Planejamento E } \\
\text { Desenvolvimento }\end{array}$ & B3 \\
\hline 06 & $\begin{array}{l}\text { Almeida Junior \& Pinto } \\
\qquad(2015)\end{array}$ & $\begin{array}{l}\text { O direito de petição e o processo administrativo como } \\
\text { instrumentos de salvaguarda da cidadania e da dignidade } \\
\text { da pessoa humana }\end{array}$ & Horizonte Científico & B4 \\
\hline 07 & $\begin{array}{l}\text { Limberger \& Kossmann } \\
\text { (2016) }\end{array}$ & $\begin{array}{c}\text { O princípio constitucional da eficiência ante o Estado (in) } \\
\text { suficiente. }\end{array}$ & $\begin{array}{l}\text { Revista de Direito } \\
\text { Administrativo }\end{array}$ & A2 \\
\hline 08 & $\begin{array}{l}\text { Siqueira \& Rosolen } \\
\text { (2017) }\end{array}$ & $\begin{array}{l}\text { Governança do estado e o direito (dever) à boa } \\
\text { administração pública: a regra da observância aos } \\
\text { preceitos constitucionais }\end{array}$ & Argumentum (UNIMAR) & B1 \\
\hline 09 & Dezan \& Carmona (2017) & $\begin{array}{c}\text { A Ilusória Amorfia do Processo } \\
\text { Administrativo Sancionador: o Princípio } \\
\text { da Instrumentalidade das Formas vs. as } \\
\text { Finalidades do Processo, sob o Amparo da Ética, da Moral } \\
\text { e da Complexidade }\end{array}$ & $\begin{array}{l}\text { Direito, Estado e Sociedade } \\
\text { (impresso) }\end{array}$ & B3 \\
\hline 10 & Aguiar \& Haber (2017) & $\begin{array}{l}\text { Controle jurídico das políticas públicas: uma análise a } \\
\text { partir dos conceitos de eficácia, efetividade e eficiência }\end{array}$ & $\begin{array}{l}\text { A\&C. Revista de d. } \\
\text { Administrativo \& } \\
\text { Constitucional }\end{array}$ & A2 \\
\hline 11 & $\begin{array}{l}\text { Fortini \& Shermam } \\
\qquad(2017)\end{array}$ & $\begin{array}{l}\text { Governança pública e combate à corrupção: novas } \\
\text { perspectivas para o controle da Administração Pública } \\
\text { brasileira }\end{array}$ & Revisa Interesse Público & B4 \\
\hline 12 & Rezende (2016) & $\begin{array}{l}\text { Mecanismos inquisitivos do PAD federal (Lei Federal } \mathrm{n}^{\circ} \\
8.112 / 1990)\end{array}$ & $\begin{array}{l}\text { Revista de Direito } \\
\text { Administrativo }\end{array}$ & A2 \\
\hline 13 & Menezes (2017) & $\begin{array}{c}\text { A incidência do Código de Processo Civil e de princípios } \\
\text { constitucionais de processo civil nos PAD de servidores } \\
\text { públicos federais }\end{array}$ & Revista Controle & B4 \\
\hline 14 & Gomes (2014) & $\begin{array}{l}\text { Responsabilidade administrativa do servidor público na } \\
\text { administração pública federal }\end{array}$ & $\begin{array}{l}\text { Adm. Made (Universidade } \\
\text { Estácio De Sá) }\end{array}$ & B2 \\
\hline 15 & Dezan \& Carmona (2015) & $\begin{array}{l}\text { O PAD e os pressupostos processuais sob a égide da nova } \\
\text { processualidade civilista (Lei } 13.105 / 2015)\end{array}$ & $\begin{array}{l}\text { R. Eletrônica de Direito } \\
\text { Processual }\end{array}$ & B1 \\
\hline 16 & Haonat (2015) & Processo Administrativo e Garantias Constitucionais & Revista ESMAT & B4 \\
\hline 17 & May \& Filó (2015) & $\begin{array}{c}\text { Os princípios do contraditório e da ampla defesa como } \\
\text { instrumentos históricos garantidores da eficácia e } \\
\text { legitimidade do PAD }\end{array}$ & $\begin{array}{l}\text { Revista de Direitos e } \\
\text { Garantias Fundamentais }\end{array}$ & A1 \\
\hline 18 & Teixeira (2017) & $\begin{array}{l}\text { O Termo de Ajustamento de Gestão no controle eficiente } \\
\text { da Administração Pública }\end{array}$ & Revista Controle & B4 \\
\hline 19 & Pereira \& Pereira (2016) & Processo administrativo disciplinar e suas penalidades & $\begin{array}{l}\text { Revista da Universidade } \\
\text { Vale do Rio Verde }\end{array}$ & B3 \\
\hline 20 & Rodrigues (2017) & $\begin{array}{c}\text { Democracia vs. eficiência: como alcançar equilíbrio em } \\
\text { tempo de crise financeira }\end{array}$ & $\begin{array}{l}\text { Revista de Administração } \\
\text { Pública }\end{array}$ & A2 \\
\hline
\end{tabular}

Fonte: Autores (2021).

Conforme Quadro 1, para identificar a classificação CAPES (Qualis) das revistas, foi feita uma consulta através da Plataforma Sucupira. Para tanto considerou-se a avalição do quadriênio 2013-2016 (classificação vigente). As publicações listadas foram nas áreas de Administração pública e de empresas, ciências contábeis e turismo e na área de Direito, analisadas através do tema principal do artigo. Identificou-se seis periódicos com classificação B3; seis com classificação B4; cinco com 
classificação A2; dois com classificação B1; um com classificação B2; e, um com classificação A1.

Ainda observando o Quadro1 foram identificadas 17 revistas científicas diferentes, onde foram publicados os 21 artigos listados. A revista com maior número de artigos publicados foi a A\&C. Revista de Direito Administrativo \& Constitucional, com três publicações. Esta revista tem a classificação Qualis A2, na área do Direito e B4 na área de Administração Pública e de Empresas, Ciências Contábeis e Turismo, conforme a Classificação de Periódicos Quadriênio 2013-2016. A linha editorial desta revista desenvolve pesquisas voltadas as áreas do Direito Constitucional e de Direito Administrativo, visando a efetividade dos seus institutos e com destaque para o campo de intersecção entre Administração Pública e Constituição e a análise crítica das inovações em matéria de Direito Público, levando em consideração a questão geografia preferencialmente América Latina e países europeus de cultura latina. Com relação ao ano de publicação dos artigos, destaca-se o ano de 2017 com 07 publicações, sendo que este é também o ano mais recente entre os artigos do quadro, seguido do ano de 2015 com 06 publicações e 2016 com 03 publicações, isso demonstra uma atualidade e interesse sobre a temática pesquisada, além do crescimento da pesquisa nos últimos 05 anos.

Os artigos selecionados versam sobre os temas que envolvem o objeto de estudo. Sendo assim pode-se destacar, pela leitura dos títulos, quatro temáticas: Administração Pública, Eficiência Administrativa, Processo Administrativo e Processo Administrativo Disciplinar.

Na temática de Administração Pública identifica-se 02 artigos, os de código 08 e 11. Com relação a Eficiência Administrativa identifica-se 05 artigos, os de código 02, 07, 10, 18 e 20. Para a temática Processo Administrativo, identifica-se 05 artigos, sendo eles os de código 03, 04, 05, 06 e 16. Por fim, a temática Processo Administrativo Disciplinar identifica-se 08 artigos, os de código 01, 09, 12, 13, 14, 15, 17 e 19.

O Quadro 2 traz os objetivos e as principais considerações finais apresentadas pelos autores para cada um dos 20 artigos selecionados para esse trabalho.

Quadro 2 - Objetivo e Principais considerações finais dos artigos selecionados.

\begin{tabular}{|c|c|c|}
\hline Cod. & Objetivo & Principais considerações \\
\hline 01 & $\begin{array}{l}\text { Examinar a necessidade de defesa } \\
\text { técnica no PAD e a } \\
\text { inconstitucionalidade da Súmula } \\
\text { vinculante } \mathrm{n}^{\circ} 5 \text { do STF. }\end{array}$ & $\begin{array}{l}\text { O art. } 156 \text { da Lei } 8.112 / 90 \text { enuncia o direito à autodefesa e à defesa técnica como } \\
\text { elementos indissolúveis do princípio constitucional da ampla defesa. A Súmula } \\
\text { Vinculante } n^{\circ} 5 \text { ostenta graves vícios de inconstitucionalidade, além dos vícios } \\
\text { formais, constitui inobjetável exigência do direito fundamental à ampla defesa no } \\
\text { PAD. }\end{array}$ \\
\hline 02 & $\begin{array}{l}\text { Apresentar os conceitos sobre } \\
\text { eficiência, e como o termo "eficiência" } \\
\text { virou um princípio adotado na } \mathrm{CF} / 88 \text {. }\end{array}$ & $\begin{array}{l}\text { O princípio da eficiência deu um novo formato na gestão pública, criando novos } \\
\text { padrões de trabalhos, visualizando resultados rápidos, com perfeição e rendimento } \\
\text { funcional. Após dez anos de reforma, a Administração Pública sofreu importantes } \\
\text { transformações e está se tornando realmente eficiente. }\end{array}$ \\
\hline 03 & $\begin{array}{l}\text { Analisar o regime jurídico estatuído } \\
\text { pela Lei } n^{\circ} 9.784 / 99, \text { a partir das } \\
\quad \text { exigências constitucionais. }\end{array}$ & $\begin{array}{l}\text { O processo administrativo representa o veículo por excelência de atuação da } \\
\text { Administração Pública. A investigação revela-se necessária para demonstrar que } \\
\text { ainda há matérias de grande relevância que não encontram na jurisprudência } \\
\text { acolhida mais consentânea ao ideal contido na Constituição de } 1988 \text {. }\end{array}$ \\
\hline 04 & $\begin{array}{l}\text { Apresentar o instituto do precedente } \\
\text { administrativo como maneira de } \\
\text { justificação das decisões } \\
\text { administrativas a partir da Lei } 9.784 / 99 \text {. }\end{array}$ & $\begin{array}{c}\text { A aplicação do precedente administrativo tem como base a Lei 9.784/99, aliado aos } \\
\text { princípios gerais da eficiência e de boa governança. O tema do precedente } \\
\text { administrativo ganha novos contornos a partir da vigência do Novo CPC, } \\
\text { apresentando algumas novas regras que formam um regime processual do } \\
\text { precedente. }\end{array}$ \\
\hline 05 & $\begin{array}{l}\text { Verificar o trâmite processual em uma } \\
\text { instituição pública, e os princípios } \\
\text { administrativos relacionados a tais } \\
\text { práticas. }\end{array}$ & $\begin{array}{l}\text { A observância e a obediência a tais princípios, evita a crescente anulação dos } \\
\text { processos administrativos que tramitam nas instituições públicas. Os atos praticados } \\
\text { por servidores públicos estarão respaldados por normas, regras e orientações, com } \\
\text { isso, evita-se desperdício de tempo, material e recursos humanos, para evitar vícios } \\
\text { nos Atos. }\end{array}$ \\
\hline 06 & $\begin{array}{l}\text { Analisar o processo administrativo e o } \\
\text { direito de petição enaltecendo suas } \\
\text { funções de salvaguarda constitucionais. }\end{array}$ & $\begin{array}{l}\text { Direito de petição permite a concretização da participação dos administrados no } \\
\text { cerne da Administração Pública. Processo administrativo é instrumento de defesa de } \\
\text { direitos individuais. Nesta esteira, toda limitação à esfera individual dos } \\
\text { administrados será precedida de regular processo administrativo. }\end{array}$ \\
\hline
\end{tabular}




\begin{tabular}{|c|c|}
\hline 07 & $\begin{array}{l}\text { Analisar em que consiste o princípio da } \\
\text { eficiência no contexto brasileiro. }\end{array}$ \\
\hline 08 & $\begin{array}{l}\text { Apresentar uma breve análise dos } \\
\text { princípios da boa governança como } \\
\text { forma de concretização à boa } \\
\text { Administração. }\end{array}$ \\
\hline 09 & $\begin{array}{l}\text { Analisar a inter-relação entre o } \\
\text { processo administrativo disciplinar e os } \\
\text { princípios da instrumentalidade das } \\
\text { formas ou do formalismo moderado. }\end{array}$ \\
\hline 10 & $\begin{array}{c}\text { Debater o controle de políticas públicas, } \\
\text { quanto ao alcance de resultados na } \\
\text { sociedade. }\end{array}$ \\
\hline 11 & $\begin{array}{l}\text { Examinar como o controle interno da } \\
\text { Administração Pública pode aprimorar } \\
\text { com mecanismos de governança. }\end{array}$ \\
\hline 12 & $\begin{array}{l}\text { Investigar o PAD dentro de sua } \\
\text { configuração constitucional, } \\
\text { entendendo como seu sistema } \\
\text { processual está estruturado. }\end{array}$ \\
\hline 13 & $\begin{array}{l}\text { Examinar as normas legais que } \\
\text { legitimam a aplicação dos dispositivos } \\
\text { do CPC e de princípios constitucionais } \\
\text { de direito processual civil em PAD. }\end{array}$ \\
\hline 14 & $\begin{array}{l}\text { Examinar algumas garantias do acusado } \\
\text { no processo administrativo, o qual é } \\
\text { utilizado para externar o poder } \\
\text { disciplinar da autoridade administrativa. }\end{array}$ \\
\hline
\end{tabular}

Estudar os novos contornos deferidos ao direito administrativo, especialmente ao processo disciplinar, com o advento da Lei 13.105/2015.

Investigar se a marcha do processo

administrativo observa os ditames constitucionais e se a ele se aplica a Teoria Geral do Direito.

Analisar o Processo Administrativo Disciplinar sobre a ótica da Teoria Garantista de Ferrajoli.

Analisar o instituto jurídicoadministrativo do Termo de

Ajustamento de Gestão, perante o princípio da eficiência na administração pública.

Demonstrar as formas procedimentais do processo administrativo disciplinar, através de lições trazidas por doutrinadores administrativistas e jurisprudências pátrias.

Analisar a relação e tensão entre a recente crise financeira global.

A eficiência administrativa somente pode acontecer como resultado de uma boa administração. No Estado brasileiro, considerando os preceitos constitucionais a verificação de sua eficiência somente ocorrerá com cumprimento da Constituição. Os princípios da boa governança resultam na governabilidade do Estado e permite a participação da sociedade civil e a confiança dos cidadãos. A conjugação do direito à

boa administração pública com os princípios da boa governança resultam na governabilidade, com a respectiva participação da sociedade civil.

O princípio do formalismo moderado, ou da instrumentalidade das formas, são empregados de modo indistinto para a garantia de um direito material. O processo e o direito material devem-se encontrar em mesmo nível de importância e de funcionalidade dentro do sistema de normas à luz da CF/88 e de seus princípios.

As políticas públicas já não bastam serem válidas e justas, necessário que sejam eficazes na promoção do bem-estar. Através da teoria analítico-comportamental, foi apresentada uma nova ferramenta de análise crítica das políticas públicas.

Identificou-se a governança como instrumento hábil de controle da corrupção, problema existente premente na agenda pública brasileira. Tais medidas precisam ser efetivamente fomentadas e implementadas pelos gestores públicos para que produzam os efeitos.

A legislação impõe as garantias processuais, porém os mecanismos inquisitivos do PAD tornam inócuos tais intentos. Deve-se alterar a forma com está, e a chave para isso é a cautela pela primazia do princípio dispositivo e a forte mitigação dos mecanismos inquisitivos do PAD.

Não se deve aplicar de pronto dispositivos do CPC se o próprio regramento administrativo se revelar bastante para solucionar as lides. Pôde-se vislumbrar a cogência na incidência dos ditames do CPC em processos administrativos disciplinares de maneiras subsidiária e supletiva.

Nota-se que na maioria das vezes, os membros das comissões não têm condições técnicas e nem psicológicas para condução de um processo disciplinar. Os

legisladores têm de começar a pensar em delinear um novo modelo de processo disciplinar no sentido de dar maiores poderes para as comissões de processo e, ainda, repensar o modelo de que dispõe a administração para apuração dos ilícitos administrativos.

Atos administrativos processuais, por vezes e por mais que possuam a mesma essência de seus similares atos materiais, produzem efeitos jurídicos específicos a mercê do ambiente processual. o processo levado a efeito pela Administração Pública encontra-se em franco aprimoramento de seus institutos e categorias e, sob esse prisma, a teoria geral do processo e a teoria geral do processo civil têm participação fulcral.

Administração Pública resiste em reconhecer a igualdade entre processo administrativo e jurisdicional e a Teoria Geral do Direito deve ser observada. Essa Administração deve atuar com base nos princípios da segurança e da confiança, do devido processo legal, da ampla defesa, do contraditório e do juiz natural.

A iniciativa de punição da Administração Pública não pode fugir das garantias constitucionais do contraditório e da ampla defesa, mesmo na Sindicância. O PAD deve ser garantidor do contraditório e da ampla defesa, para legitimidade e eficácia.

Percebe-se hoje um direcionamento, não apenas da administração pública, mas da sistemática jurídica contemporânea, para a resolução consensual de conflitos. $\mathrm{O}$

Termo de Ajustamento de Gestão cumpre parcialmente com os atributos da eficiência, sendo uma alternativa viável à punição.

Pelo PAD se aplica ao servidor penalidades, podendo ser revistas pelo Poder Judiciário somente quanto ao devido processo legal e sobre o aspecto relacionado à competência. Esse instrumento deve ser usado de forma responsável em conformidade com os ditames legais, para que seja prestado de forma eficiente.

$\mathrm{O}$ argumento de uma relação linear inversa de desempenho financeiro e procedimentos democráticos. A crise financeira evidenciou o efeito negativo dos procedimentos democráticos no desempenho financeiro.

Fonte: Autores (2021).

Como retratado anteriormente pode-se identificar quatro temáticas tratadas pelos autores dos artigos selecionados, Administração Pública, Eficiência Administrativa, Processo Administrativo e Processo Administrativo Disciplinar. O Quadro 2 
traz os objetivos e as principais considerações finais dos artigos, o que, conforme o agrupamento por temática proposto, passamos a analisar.

\section{- Administração Pública:}

Nessa temática identificou-se os artigos de código 08 e 11 . O artigo 08 traz como resultado que os princípios da boa governança resultam na governabilidade do Estado e que permite a participação da sociedade civil. Já o artigo 11 traz a governança como instrumento hábil de controle da corrupção e que as medidas relacionadas a governança devem ser implementadas pelos gestores públicos com o fito de produzir efeitos. Ambos os artigos trazem o tema governança ligada a boa administração.

\section{- Eficiência Administrativa:}

Para essa temática identificou-se os artigos de código 02, 07, 10, 18 e 20. O artigo 02 com o objetivo de apresentar conceitos sobre eficiência e como esse termo virou um princípio, traz que a administração pública está em constante transformação e que o princípio da eficiência trouxe novo formato, aperfeiçoando os resultados. Já o artigo 07 objetivando analisar o princípio da eficiência no contexto brasileiro, retrata como resultado dessa análise que a eficiência está ligada a boa administração e a verificação dessa eficiência somente pode ocorrer com o cumprimento da Constituição. $\mathrm{O}$ artigo 10 com o intento de debater o controle das políticas públicas quanto ao alcance de resultados, traz como resultado dessa pesquisa que já não basta que a política pública seja justa e válida, mas sim que apresente resultados eficazes para a sociedade. O artigo 18 apresenta como objetivo analisar o Termo de Ajustamento de Gestão perante o princípio da eficiência e traz como resultado que este instrumento cumpri parcialmente com os atributos da eficiência, mas que existe uma tendência, na esfera pública, de buscar a resolução de conflitos de forma consensual. Por fim o artigo 20 objetivando analisar a relação entre eficiência e democracia a luz da atual crise financeira, retrata que existe uma relação linear inversa entre desempenho financeiro e democracia. Neste contexto cabe ressaltar que ao longo das escritas dos artigos foram embasados alguns mecanismos e instrumentos introduzidos na administração pública através das mudanças que esta vem sofrendo ao logo dos anos. Pode-se inferir que os artigos listados nessa temática relacionam a eficiência administrativa com resultados eficazes para sociedade.

\section{- Processo Administrativo:}

Nesta temática foram identificados 05 artigos, os de código 03, 04, 05, 06 e 16. O artigo 03 objetivando analisar a Lei № 9.784/99 a partir das exigências constitucionais, traz como resultado que o processo administrativo é o veículo apropriado para atuação da Administração Pública e que a pesquisa foi importante para demonstrar que há matérias que não encontram respaldo jurisprudencial ao ideal contido na CRFB de 1988. No artigo 04, no intuito de apresentar o instituto do precedente administrativo como maneira de justificação das decisões administrativas, trouxe como resultado que a base do citado precedente é a Lei No 9784/99 juntamente aos princípios gerais da eficiência e boa governança, e que com o novo Código de Processo Civil (CPC) este instituto ganha novas regras. O artigo 05 propôs verificar o trâmite processual em uma repartição pública e a observância dos princípios relacionados. Como resultado constatou-se que a observâncias aos princípios administrativos relacionados as práticas processuais evitam a crescente anulação de processos administrativos e por consequência evitam o desperdício de tempo, material e recursos humanos. No artigo 06 com o objetivo de analisar o processo administrativo e direito de petição, foi argumentado que o processo administrativo é um instrumento de defesa de direito individuais. Dessa forma, este instrumento deverá preceder a toda limitação à esfera individual perante a administração pública. Por fim, o artigo 16, com a intenção de investigar a marcha processual administrativa diante dos ditames constitucionais e da Teoria Geral do Direito, conclui que a Administração Pública resiste em reconhecer a igualdade entre 
processo administrativo e jurisdicional e que se esquece que a Teoria Geral do Direito é una, portanto deve ser aplicada a ambos. Pode-se inferir que os artigos 03 e 06 trazem a legitimidade do processo administrativo como instrumento de garantia dos direitos individuais perante a administração pública. Os artigos 4 e 5 relacionam o processo administrativo aos princípios processuais e gerais, inclusive como condição para evitar anulações de atos. No artigo 16 emerge a isonomia entre os processos administrativo e jurisdicional.

\section{- Processo Administrativo Disciplinar (PAD):}

Nesta temática foram identificados 08 artigos, os de código 01, 09, 12, 13, 14, 15, 17 e $19 . \mathrm{O}$ artigo de código 01 no intuito de examinar a necessidade de defesa técnica no PAD, traz que o Art. 156 da Lei 8.112/90 enuncia que a autodefesa e defesa técnica são direitos consagrados pelo princípio constitucional da ampla defesa e que a Sumula $\mathrm{n}^{\circ} 5$ do STF ostenta vários vícios. Já no artigo 09 ao analisar a relação do PAD e os princípios da instrumentalidade das formas e do formalismo moderado, destaca que esses dois princípios têm sido empregados de modo indistinto, dando-lhe estrutura rígida. No artigo 12 , investigando o PAD dentro da sua configuração constitucional, foi retratado que apesar da legislação vigente impor as garantias processuais, os mecanismos inquisitivos do PAD tornam-nas inócuas, e que essa situação deve ser mudada, mitigando tais mecanismos e a cautela pela primazia do princípio dispositivo. $\mathrm{O}$ artigo 13, como o objetivo de examinar as normas legais que legitimam a aplicação do CPC e os princípios constitucionais de direito civil ao PAD, traz que o CPC deve ser aplicado de forma subsidiária e supletiva. O artigo 14 com a intenção de examinar algumas garantias do acusado no PAD, retratou que os legisladores devem começar a pensar em um novo modelo de PAD, no sentido de dar mais poderes as comissões processantes e uma nova forma de apuração dos ilícitos administrativos. O artigo 15 , no intuito de estudar os contornos do direito administrativo, principalmente com relação ao PAD com o advento da Lei 13.105/2015, traz como consideração que os Atos administrativos processuais produzem efeitos distintos dos atos materiais e que o processo administrativo se encontra em aprimoramento, e sobre esse prisma, a teoria geral do processo e a teoria geral do direito têm grande participação. O artigo 17 tratou de analisar o PAD sobre a ótica da Teoria Garantista de Ferrajoli e constatou que o PAD deve ser um instrumento garantidor do contraditório e da ampla defesa para ter legitimidade e eficácia. O artigo 19, com o objetivo de demostrar as formas procedimentais do PAD, trouxe que o PAD é um dos meios pelo qual se aplica penalidades ao servidor. Para que PAD seja eficiente a administração deve utilizá-lo de forma responsável e em conformidade com os ditames legais. Analisando o que foi exposto nesta temática pode-se perceber que os artigos 01 e 17 ressaltaram a importância das garantias da ampla defesa e contraditório no PAD e o artigo 12 corroborando com esse entendimento destaca que a legislação vigente impõe as garantias processuais ao PAD. Os artigos 09 e 14 apontam problemas com a forma da condução do PAD, seja por aplicação indistinta dos princípios da instrumentalidade das formas e do formalismo moderado como pelo fato de que o modelo atual do PAD não é suficiente para apuração de todos os atos infracionais cometidos por servidor público. Os artigos 13 e 15 dispuseram sobre a parte processual do PAD, mostrando que a Teoria Geral do Processo, a Teoria Geraldo do Direito e o CPC devem ser subsídios na condução do PAD. O artigo 19 consolida esse entendimento colocando de forma clara que o PAD somente será eficiente se observar todos os ditames legais.

\section{Considerações Finais}

Este trabalho teve como objetivo verificar a partir de uma revisão integrativa como está caracterizada a eficiência administrativa no contexto da administração pública, processo administrativo e princípio da eficiência aplicados ao processo administrativo disciplinar, levando em consideração artigos com Qualis CAPES A1 a B4, publicados no período de 2010 a 2020.

Foi discutido sobre a evolução da forma de agir da administração pública frente aos seus administrados. Estas 
transformações foram influenciadas tanto pelas experiências de outros países quanto da administração privada brasileira. Entre estas transformações destaca-se a inclusão do princípio da eficiência.

Posteriormente, buscou-se embasamento teórico sobre a eficiência na esfera administrativa. Entende-se que eficiência no serviço público se faz necessária para cumprir o principal fim do Estado que é o bem-estar social, e isso só será possível com a utilização dos recursos de forma racional e com eficácia. Dando sequência, as temáticas Processo Administrativo e PAD, discutiu-se como estes vêm sendo conduzidos após a inclusão do princípio da eficiência no rol dos princípios da Administração Pública.

Para tanto buscou-se responder o seguinte problema de pesquisa: como está caracterizada a eficiência administrativa no contexto da administração pública, processo administrativo e princípio da eficiência aplicados ao processo administrativo disciplinar?

Levando em consideração as contribuições para esta pesquisa, a partir do referencial teórico e dos artigos pesquisados na análise textual (envolvendo principalmente os objetivos e considerações relevantes), pode-se identificar que:

- A Eficiência na Administração Pública está ligada a boa administração e às políticas públicas que trazem resultado eficazes para a sociedade;

- O Processo Administrativo reconhecidamente está no mesmo patamar do processo judicial, conforme preconiza a CRFB de 1988. Neste contexto, ambos os processos têm as mesmas garantias principológicas e constitucionais, até mesmo como forma de evitar anulações dos atos processuais administrativos. Porém a Administração Pública é resistente em reconhecer essa isonomia;

- O PAD, por seu caráter sancionador, deve ser conduzido com maior responsabilidade, evitando a aplicação de forma indistinta dos princípios da instrumentalidade das formas e do formalismo moderado, utilizando o CPC, a Teoria Geral do Direito e Teoria Geral do Processo de forma subsidiária e principalmente, garantir a plenitude dos princípios da ampla defesa e do contraditório. Foi identificado que a atual forma de condução PAD não atende as garantias processuais e constitucionais, seja pelo seu caráter inquisitivo e/ou pela limitação legislativa para apurar determinadas infrações disciplinares.

Sugestões para trabalhos futuros:

- Como proposta para pesquisas futuras sugere-se pesquisas envolvendo a parte processual da Administração Pública e as mudanças constantes na letra da lei, com a intenção de alcançar o dinamismo desta relação; estudos empíricos sobre a aplicação das garantias processuais constitucionais no processo administrativo; estudos sobre causas mais constantes de anulação do PAD nas repartições públicas, pelo poder judiciário; estudos empíricos sobre a eficiência administrativa na condução do PAD.

Por fim, espera-se que essa pesquisa possa contribui para ampliar o embasamento da temática envolvendo o princípio da eficiência e o processo administrativo disciplinar, promovendo o aumento dos debates e discussões nas publicações sobre essa temática que se apresenta crescente nos últimos anos, tendo em vista sua relevância.

\section{Referências}

Abrucio, F. L. (2007). Trajetória recente da gestão pública brasileira: um balanço crítico e a renovação da agenda de reformas. Revista de Administração Pública. Edição Especial Comemorativa, 67-86. https://www.scielo.br/pdf/rap/v41nspe/a05v41sp.pdf

Aguiar, J. C., \& Haber, M. T. (2017). Controle jurídico das políticas públicas: uma análise a partir dos conceitos de eficácia, efetividade e eficiência. Revista de Direito Administrativo \& Constitucional, 70 (17), 257-280. 10.21056/aec.v17i70.823

Almeida Junior, E. C. \& Pinto, M. A. S. (2015). Direito de petição e o processo administrativo como instrumento de salvaguarda da cidadania e da dignidade da pessoa humana. Revista Horizonte Científico, 9(2), 1-25. http://www.seer.ufu.br/index.php/horizontecientifico/article/view/18067

Bacellar Filho, R. F., \& Hachem, D. W. (2010). A necessidade de defesa técnica no processo administrativo disciplinar e a inconstitucionalidade da Súmula Vinculantes $\mathrm{n}^{\circ} 5$ do STF. Revista de Direito Administrativo \& Constitucional, 10(39), 27-64. http://www.revistaaec.com/index.php/revistaaec/article/view/288/141 
Bacellar Filho, R. F.. \& Pivetta, S. L. (2014). O regime jurídico do processo administrativo na Lei no 9.784/99. Revista de Direito Administrativo \& Constitucional, 14(58), p. 107-135. http://www.revistaaec.com/index.php/revistaaec/article/view/75/336

Barros, M. A. L. L. (2015). Processo, precedentes e as novas formas de justificação da Administração Pública Brasileira. Revista Digital de Direito Administrativo, 3(1), 133-149. https://www.revistas.usp.br/rdda/article/view/102556/107562

Bocchino, L. O. et al. (2016). Processos apuratórios relativos à conduta de servidor público federal. Curitiba: Editora UTFPR.

Botelho, L. L. R., \& Cunha, C. C. de A. \& Macedo, M. (2011). O método da revisão integrativa nos estudos organizacionais. Revista Gestão e Sociedade, 5(11), 121-136. 10.21171/ges.v5i11.1220

Camargo, F. de O., \& Guimarães, K. M. S. (2013). O princípio da eficiência na gestão pública. Revista CEPPG- Centro de Ensino Superior de Catalão, 16(28), 133-145. http://www.portalcatalao.com/painel_clientes/cesuc/painel/arquivos/upload/downloads/376b38ef01c9b0caae5d67f8c6bf4d03.pdf

Cândido Júnior, J. O. (2011). Os gastos públicos no Brasil são produtivos? Planejamento e Políticas Públicas PPP. Diretoria de Estudos Macroeconômicos DIMAC /IPEA, 23. 233-260. http://www.ipea.gov.br/ppp/index.php/PPP/article/viewFile/77/88

Carvalho, N. G. G. de, Assunção, M. V. D. de, Fernandes, D. R. M., \& Silveira, M. L. da S. S. (2020). Gestão de custos como instrumento de eficiência no âmbito do Ministério Público do Estado do Rio Grande do Norte. Research, Society and Development, 9(8), e412985473. https://doi.org/10.33448/rsdv9i8.5473

Cury-Mendes, C. C. (2015). Princípios do processo administrativo federal e a formalidade dos atos processuais: uma discussão com foco no desenvolvimento. Revista Brasileira de Planejamento e Desenvolvimento, 4(41), 132-147. https://periodicos.utfpr.edu.br/rbpd/article/view/3528/2778

Dantas, M. C., \& Silva, M. V. da. (2019). Análise da eficiência dos gastos públicos com educação básica: um estudo na microrregião Borborema PotiguarRN. Research, Society and Development, 8(2), e3582782. https://doi.org/10.33448/rsd-v8i2.782

Dezan, S. L. \& Carmona, P. A. C. (2015). O processo administrativo disciplinar e os pressupostos processuais sob a égide da nova processuallidade civilista. Revista Eletrônica de Direito Processual, 18(7), 516-545. https://www.e-publicacoes.uerj.br/index.php/redp/article/view/25178/21010

Dezan, S. L. \& Carmona, P. A. C. (2017). A Ilusória Amorfia do Processo Administrativo Sancionador: o Princípio da Instrumentalidade das Formas vs. as Finalidades do Processo, sob o Amparo da Ética, da Moral e da Complexidade. Revista Direito, Estado e Sociedade, 50, 208-232. http://direitoestadosociedade.jur.puc-rio.br/media/artigo\%209.pdf

Di Pietro, M. S. Z. (2014). Direito administrativo. (27a ed.), Atlas.

Fortini, C., \& Shermam, A. (2017). Governança pública e combate à corrupção: novas perspectivas para o controle da Administração Pública brasileira. Revista Interesse Público - IP, 19(102), 27-44. https://www.editoraforum.com.br/wp-content/uploads/2017/05/governanca-combate-corrupcao.pdf

Gomes, R. G. (2014). Responsabilidade Administrativa do Servidor Público na Administração Pública Federal. Revista Prisma Jurídico, 13(1), 193-212. http://capa.tre-rs.gov.br/arquivos/GOMES_Responsabilidade_administrativa.pdf

Haonat, Â. I. (2015). Processo administrativo e garantias constitucionais. Revista ESMAT, 4(41), 132-147. http://esmat.tjto.jus.br/publicacoes/index.php/revista_esmat/article/view/40/51

Lima, L. M. M. de. (2015). A aplicação do dever de eficiência à administração pública tributária e sua relação com a moral tributária dos contribuintes. Revista Digital de Direito Administrativo, 2(1), 273-292. 10.11606/issn.2319-0558.v2n1p273-292

Limberger, T., \& Kossmann, E. L. (2016). O princípio constitucional da eficiência ante o Estado (in) suficiente. Revista de Direito Administrativo, 273, 287311. 10.12660/rda.v273.2016.66664

Maffini, R. (2009). Direito Administrativo. (3a ed.), Revista e Atualizada. Editora Revista dos Tribunais.

May, Y. de O., \& Filó, M. da C. S. (2015). Os princípios do contraditório e da ampla defesa como instrumentos históricos garantidores da eficácia e legitimidade do processo administrativo disciplinar. Revista de Direito e Garantias Fundamentais, 16(2), 149-164. 10.18759/rdgf.v16i2.670.

Meduaur, O. (2018). Direito Administrativo Moderno. (21a ed.), Fórum Ltda.

Menezes, A. (2017). A incidência do Código de Processo Civil e de princípios constitucionais de processo civil nos processos administrativos disciplinares de servidores públicos federais. Revista Controle - Doutrina e Artigos, 15(1), 223-253, 2017. 10.32586/rcda.v15i1.359

Paula, A. P. P. de. (2005). Por uma nova gestão pública: limites e potencialidades da experiência contemporânea. Editora FGV.

Pereira, G. T., \& Pereira, L. M. (2016). Processo Administrativo Disciplinar e suas penalidades. Revista da Universidade Vale do Rio Verde, 14(1), 429-447. https://dialnet.unirioja.es/servlet/articulo? codigo $=5435419$

Rezende, M. C. de S. (2017). Mecanismos Inquisitivos do Processo Administrativo Disciplinar (Lei Federal 8.118/90). Revista de Direito Administrativo, 274(2017), 235-272. 10.12660/rda.v274.2017.68748

Rocha, D. J. (2018). Responsabilidade administrativa do servidor público por atos praticados na vida privada: limites ao processo administrativo disciplinar. Revista Projeção Direito e Sociedade, 9(2), 2018. 11-21. http://revista.faculdadeprojecao.edu.br/index.php/Projecao2/article/view/1151/981

Rodrigues, M. Â. M. (2017). Democracia vs. eficiência: como alcançar equilíbrio em tempo de crise financeira. Revista de Administração Pública, 51(1), 88104. https://doi.org/10.1590/0034-7612165400. 
Research, Society and Development, v. 10, n. 4, e29610414124, 2021

(CC BY 4.0) | ISSN 2525-3409 | DOI: http://dx.doi.org/10.33448/rsd-v10i4.14124

Saravia, E. J. (2010). Administração Pública e Administração de Empresas: quem inspira a quem?. Revista do Mestrado em Administração e Desenvolvimento Empresarial da Universidade - Revista ADM - MADE, 10(3), 1-8. www.spell.org.br/documentos/download/2637

Silva, R. S. da. (2011). O controle judicial do princípio da eficiência Administrativa. Revista de Direito da ADVOCEF, VI(12). http://www.advocef.org.br/wpcontent/uploads/2014/11/12-maio-2011.pdf\#page=149

Siqueira, D. P., \& Rosolen, A. V. (2017). Governança do estado e o direito (dever) à boa administração pública: a regra da observância aos preceitos constitucionais. Revista Argumentum, 18(3), 665-678. http://ojs.unimar.br/index.php/revistaargumentum/article/view/208/240

Sobrinho, O. P. L., \& Silva, G. S. da, Santos, L. N. S. dos, Castro Júnior, W. L., Pereira, Álvaro I. S., Teixeira, M. B., Gomes, L. F., Reis, M. N. O., \& Soares, J. A. B. (2020). Técnicas de dendrometria no manejo da irrigação: uma revisão integrativa. Research, Society and Development,9(8), e343984837. https://doi.org/10.33448/rsd-v9i8.4837

Souza, M. T. de, \& Silva, M. D. da, \& Carvalho, R. de. (2010). Revisão Integrativa: o que é e como fazer. Revista Einstein, 8(1), 102-106. 10.1590/s167945082010 rw1 134

Souza, J.P. (2015). Processo Administrativo disciplinar e os Instrumentos de economicidade à gestão pública. Dissertação de mestrado, Universidade Federal do Tocantins, TO, Brasil. 